\title{
Complement Factor D Inhibitor ACH-4471
}

National Cancer Institute

\section{Source}

National Cancer Institute. Complement Factor D Inhibitor ACH-4471. NCI Thesaurus.

Code C148181.

An orally bioavailable inhibitor of complement factor D (FD; CFD), a serine protease that cleaves complement factor B, with potential complement system inhibiting activity. Upon administration, complement FD inhibitor $\mathrm{ACH}-4471$ targets, binds to and blocks the activity of $F D$, and thereby inhibits cleavage of complement factor $B$ into $B a$ and $B b$ in the alternative pathway of the complement cascade. This inhibits FD-mediated signaling and activation of the alternative complement pathway (ACP), blocks complement-mediated hemolysis in paroxysmal nocturnal hemoglobinuria $(\mathrm{PNH})$ and prevents ACP-induced tissue damage. FD plays a key role in the activation of the ACP. 